\title{
S2 Figure
}

A

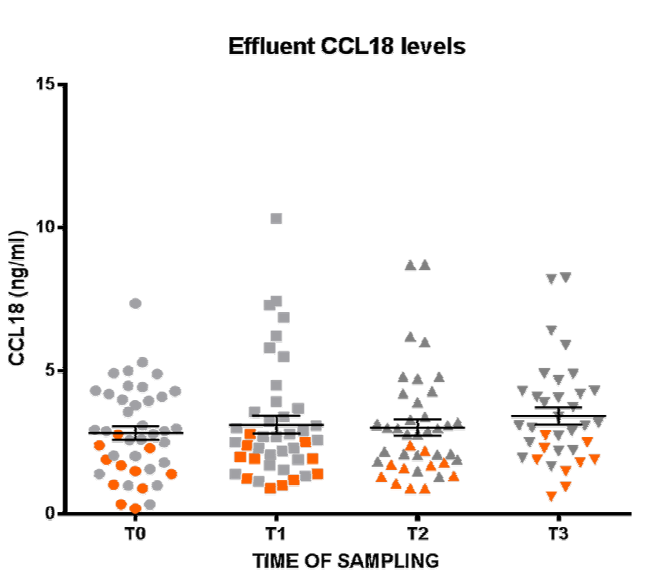

Group1:

B
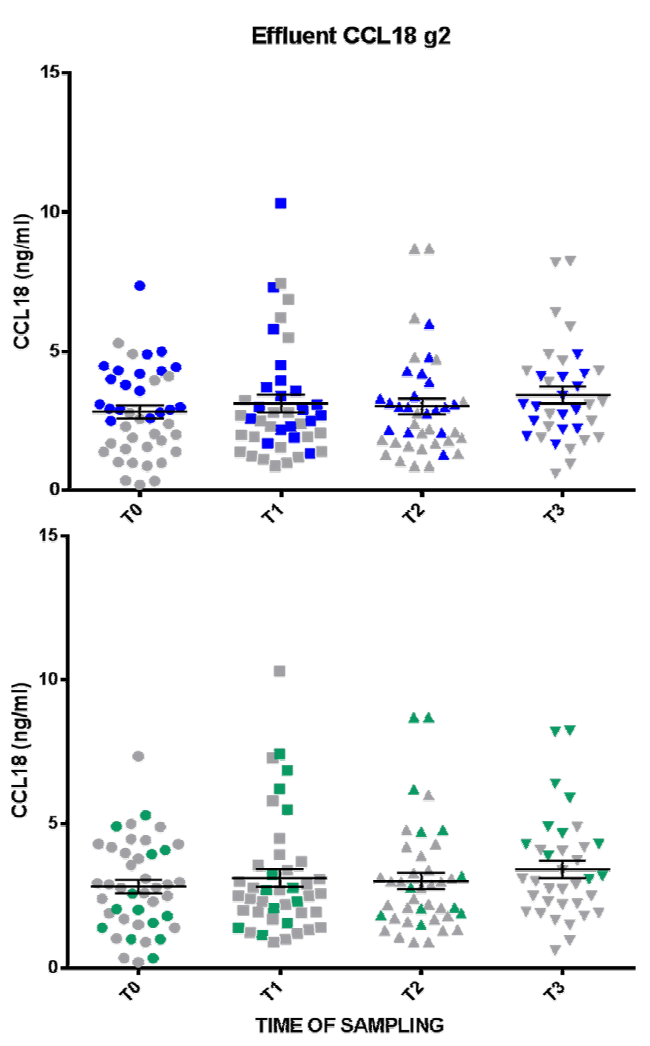

Group 2:

S2 Figure. Effluent concentrations of CCL18 in patients included in group 1 and group 2 (A) Group 1(orange symbols): CCL18 concentrations always below mean values. (B) Group 2 (blue and green symbols) Blue symbols: CCL18 concentrations equal or above mean values at T0 and or fluctuating CCL18 levels along the study. Green symbols: patients whose CCL18 effluent levels increased along the time of study. 